\title{
The Analysis of Information Management in Government Investment Projects Based on the Incomplete Information Static Game Model
}

\author{
QUAN Xuefeng ${ }^{1,}$, CHANG Mengxing ${ }^{2}$ \\ 1,2 Nanyang Medical College, Nanyang 473000, China \\ a quanxuefeng2012@126.com
}

\begin{abstract}
Keywords: Government Investment Projects; Incomplete Information Static Game Model; Game Theory
\end{abstract}

\begin{abstract}
To solve the problem of shortage of construction funds, the government try to market-oriented bidding on government investment projects. The reform of the government to take the corresponding preferential policies to attract investors to participate in enterprise through a project bidding and other forms, to create necessary conditions for the government investment project financing. With low barriers to entry, "public investment project of government investment project construction market to competitive bidding, part of the bidding enterprise, in order to get the maximum return in the bidding activities by means of unbalanced quotation, in order to strengthen the competitive power of the tender offer, for this economic phenomenon, this paper tries to analysis based on incomplete information static game model, and formulate the corresponding countermeasures.
\end{abstract}

\section{Introduction}

When more attention paid to the non-price mechanism, game theory has gradually become one of the basic analytical tools of economics. Game theory is the study of decision-making behavior direct interaction occurs in the decision-making and the balance of this decision-making problems. As a research method, game theory to penetrate and expanded the scope of the study of economics, triggered a revolution in modern economics [1]. In terms of research framework, the game theory mainly includes two parts of the cooperative game and non-cooperative game. Non-cooperative game and can be divided into complete information static game, incomplete information static game and dynamic game with complete information and incomplete information dynamic game [2].

In many areas of the economy in theoretical and applied research, game theory has become the common tools used, many economic phenomena and economic behavior were economists understanding for some kind of game problem. Game theory is a specializes in two or more individuals have a conflict of interest in the interaction case, how to carry out their respective optimization decision theory [3]. The government investment projects for the application of game theory provides a good stage. On the one hand, the various market participants try to use game theory to benefit maximization in the competition with others; Market regulation organization, on the other hand, want to use it to predict and judge under the "game" behavior of market participants, whether market manipulation, bid up the price and the unreasonable phenomenon, and shall be supervised, prevent and punish. Because of the characteristic of the government investment projects have diversified, so the game theory in government investment projects applied research has great theory value and practical guiding significance. Here we can put forward a theoretical model of game theory, to solve the problem of pricing in electricity market. We assume that an independent system run institutions accept construction company in the bidding, and through the pursuit to meet the market demand to determine the lowest price of transaction between participants.

\section{An overview of the game theory}

Game going is the study of decision-making behavior in direct interaction time decision-making and the balance of this decision-making theory [4]. That is to say, the game theory research as a 
main body, such as the choice of a person or an enterprise under the influence of others (other enterprises) choice, and in turn affect the others (other enterprises) and equilibrium problems when the choice decisions. So in this sense, the game theory is also called "game theory". Game theory is a kind of rigorous mathematical model was used to solve the theory of conflict of interest in reality, because of the conflict, cooperation and competition behavior is a common phenomenon in reality, so many areas can be used the game theory, such as military, economic, political, diplomatic, etc. Game theory and the conventional optimization decision theory differs: participants in the game theory in interest's conflict; Participants to make optimal decisions, and in an attempt to maximize the interest of the individual. There is an interaction between each person's decision-making and others, which is the decision of others affect someone, and one person's decision will affect others. Generally assume that individuals to participate in decision-making in the game theory are "rational", thus carries on the rational logical thinking, its theoretical system is shown in figure 1.

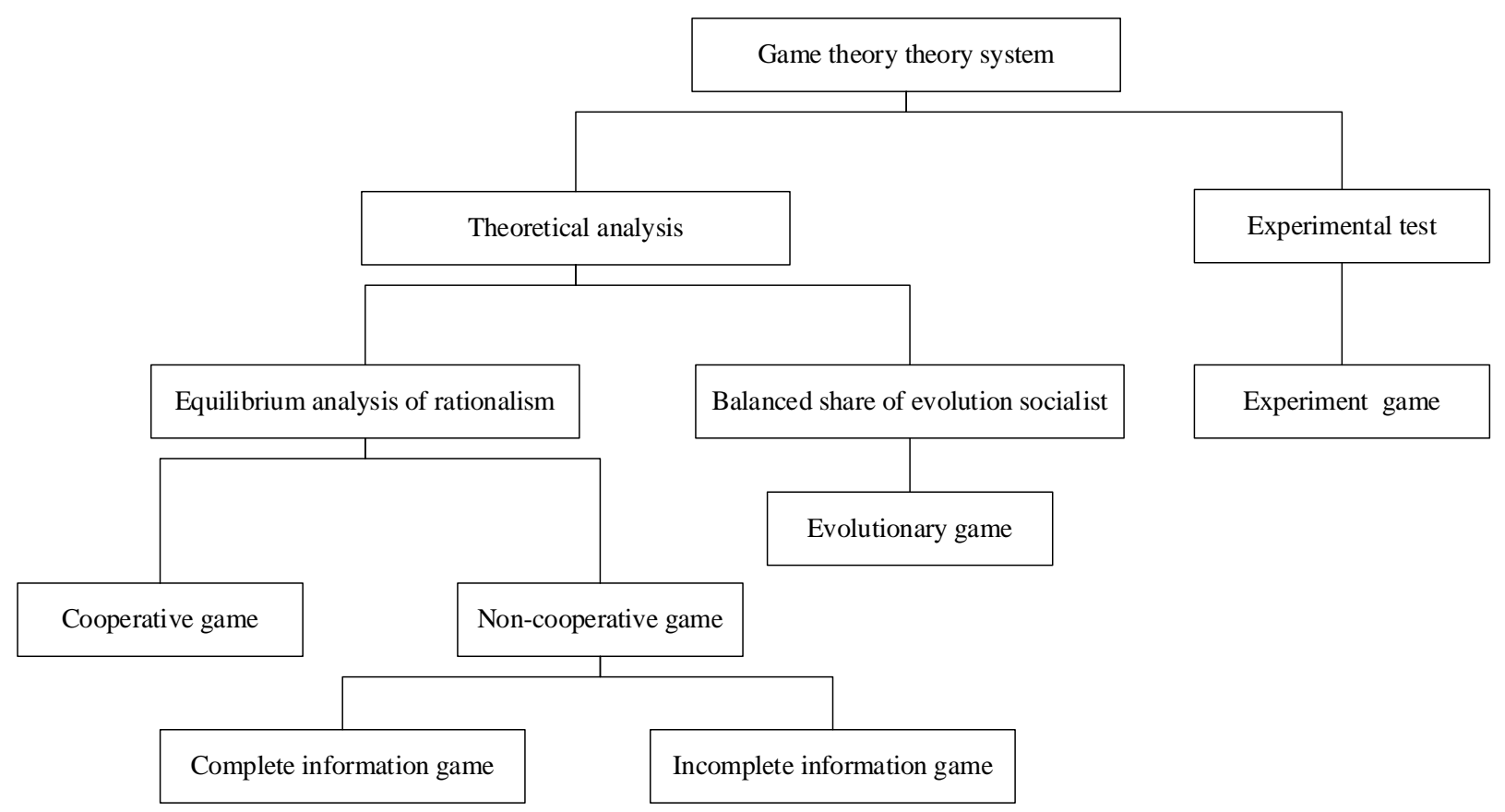

Figure 1. Theoretical system structure of game theory

In general, we are going to game the game parties fully understand all the players in a variety of circumstances to benefit from the game to become a "game with complete information, and will be in the game there are at least part of the game parties don't know other zero-sum game called game with incomplete information. At the same time, we can put all the players at the same time, or as a selection strategy game called "static game" at the same time. We put the game side not at the same time, but has, in turn to choose, action, and after the selection, action game party before they choose action in general can understand after the choice of other game parties, action game called dynamic game.

\section{Incomplete information static game model analysis}

Incomplete information game, also known as "Bayesian game after game theory in the $1970 \mathrm{~s}$ gradually entered the mainstream economics system, mainly because it is under the condition of incomplete information in economic analysis showed a special charm. In recent years, the incomplete information, the application of game theory has been extended to all fields. Incomplete information static game is game party doesn't know exactly what the other participants in the information such as the characteristics, the strategic space and payoff function, but at the same time participants must choose the action or is not at the same time but after the actors didn't know before the actors take specific action [5]. What is the method of calculating the incomplete information static game, typically by Harsanyi Transformation, it is concluded that the Nash equilibrium is the Bayesian Nash equilibrium. 
Generally used to describe the static multidimensional game strategy type, can be described as:

(1) The set of multidimensional game participants is $\Gamma, \Gamma=(1,2, \ldots, n)$ represents in multidimensional game there are n people gamble refs;

(2) Participants in the type of space is $\theta_{1}, \theta_{2}, \ldots, \theta_{n}$, belongs to type on behalf of the participants in the game. Type dependent strategy of multidimensional space is $\left.A_{1}\left(\theta_{1}\right), A_{2}\left(\theta_{2}\right), \ldots, A_{n(} \theta_{n}\right)$, depending on the type of game participants. Type dependent payoff function is $\mu_{1}\left(a_{1}, a_{2}, \ldots, a_{n} ; \theta_{1}\right), \mu_{2}\left(a_{1}, a_{2}, \ldots, a_{n} ; \theta_{2}\right), \ldots \mu_{n}\left(a_{1}, a_{2}, \ldots, a_{n} ; \theta_{n}\right)$;

Conditional probability is $\mathrm{p}_{1}, \mathrm{p}_{2}, \ldots, \mathrm{p}_{n}$, Participants $\mathrm{i}$ know its type $\theta_{i} \in \Theta_{i}$, Expressed by $\Theta_{-i}$ in addition to the type of players other than player $\mathrm{i}, \mathrm{p}_{1}\left(\Theta_{-i} \mid \Theta_{i}\right)$ is to describe $\mathrm{i}$ given itself belong to the conditional probability of cases, participants $\mathrm{i}$ on the uncertainty of other participants $\theta-{ }_{i} \in \Theta_{-i}$.

We usually use formula 1 on behalf of the game.

$$
\mathrm{G}=\left\{\mathrm{A}_{1}, \mathrm{~A}_{2}, \ldots \mathrm{A}_{n} ; \theta_{1}, \theta_{2}, \ldots, \theta_{n} ; \mathrm{p}_{1}, \mathrm{p}_{2}, \ldots, \mathrm{p}_{n} ; \mu_{1}, \mu_{2}, \ldots \mu_{n}\right\}
$$

\section{The application of the incomplete information static game model in information management of government investment projects}

In the process of a project entity bidding, the bidding process is an incomplete information static game. The bidding process has attracted 86 enterprises to participate in, the overseas enterprises accounted for $50 \%$. The government as a tenderer, 86 companies as the bidder, the bidding process between the two sides make up the whole process of game equilibrium. Because of the 86 companies on the concept of information between bids at the same time, it is static game. 86 companies know that the real value of the construction project for own enterprise $v_{i}$, but I don't know the value of the project for other enterprises, is a subjective probability to its, so is the static game of incomplete information. Project legal tender, tender offer by individual companies reported their quotation bi for this purpose, with higher price performance ratio the winning way to select the winning bidder, is a sealed auction bidding price. For the lack of the funds required for the project into some additional funding by the government, as a result, the bidding enterprise net income $\mathrm{v}_{i}-\mathrm{b}_{i}$, similar to the incomplete information static game model, companies' pay is:

$$
\begin{array}{r}
u_{i}\left(b_{i}, b_{j}, v_{i}\right)= \begin{cases}0, & b_{i}<b_{j} \\
\frac{v_{i}-b_{i}}{n}, & b_{i}=b_{j} \\
v_{i}-b_{i}, & b_{i}>b_{j}\end{cases} \\
i, j=1,2, \cdots, 114 ; \quad i \neq j
\end{array}
$$

According to the conclusion of the above model, it can be abstained in the same way

$$
b^{*}(v)=\frac{n-1}{n} v
$$

The more bidders that participate in the bidding game, companies offer $b_{i}$ tend to be more projects to them the true value of the $v_{i}$, the government will be able to get a better offer. Therefore, the government only attract more enterprises to join the project bidding, can make its investment to achieve the optimum use of. In order to maximize reduce the government financial burden and reduce the operational risk, the government assumes to attract more investors to participate in bidding, the government based on the experience of the project legal tender in advanced countries, for different projects for investment, land, preferential tariffs, etc. 


\section{Conclusion}

As a kind of research methods, penetration and expand the research scope of economics, game theory triggered a revolution in modern economics. In many areas of the economy in theoretical and applied research, game theory has become the common tools used. Government project bidding process is an incomplete information static game, incomplete information static game model, this paper analyzes the government investment in the process of bidding decision-making mechanism and its influencing factors. The study found that a new investment and financing system will be implemented to separate projects, capital, market, the mechanism of checks and balances each other, the current in each system inside a closed operation of investment system, will receive a larger reform.

\section{References}

[1] Wei S, Yang H, Abbaspour K, et al. Game theory based models to analyze water conflicts in the Middle Route of the South-to-North Water Transfer Project in China[J]. Water research, 2010, 44(8): 2499-2516.

[2] Ghapanchi A H, Tavana M, Khakbaz M H, et al. A methodology for selecting portfolios of projects with interactions and under uncertainty[J]. International Journal of Project Management, 2012, 30(7): 791-803.

[3] Roy S, Ellis C, Shiva S, et al. A survey of game theory as applied to network security[C]//System Sciences (HICSS), 2010 43rd Hawaii International Conference on. IEEE, 2010: $1-10$.

[4] Ezell B C, Bennett S P, Von Winterfeldt D, et al. Probabilistic risk analysis and terrorism risk[J]. Risk Analysis, 2010, 30(4): 575-589.

[5] Zheng X, Guo J, Chen S. Research on the project supervision game model based on the information asymmetry theory[C]//Industrial Engineering and Engineering Management, 2009. IE\&EM'09. 16th International Conference on. IEEE, 2009: 486-490. 